\title{
EFFECT OF CLIFF EROSION ON FORM OF CONTACT SURFACES
}

BY N. Ḿ. FENNEMAN

(Read before the Society December 30, 1904)

\section{CONTENTS}

The area

The area studied....................................... 205

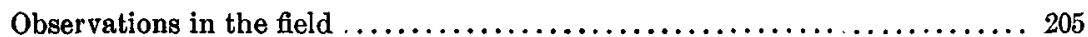

Effect of preexisting topography. ........................... 206

Factors and conditions of the problem $\ldots \ldots \ldots \ldots \ldots \ldots \ldots \ldots \ldots \ldots \ldots \ldots 206$

Illustrative cases of submergence conditions.................... 208

In general........................................ 208

Case I. Shore recession more rapid than shifting by submergence...... 208

Case II. Recession progressively retarded until its rate equals that of

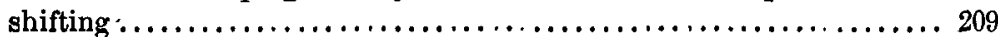

Application of case II to the area studied.................... 211

Case III. Recession less rapid than shifting by submergence........ 211

Generalization...................................... 212

The AREA studied

The occasion of this study was an attempt to determine the relations of the Wyoming Red beds to the underlying granite in the Front range of the Rocky mountains in northern Colorado. The southern half of the Boulder and the northern part of the Denver quadrangles represent the area of investigation.

\section{Observations in the Field}

It was evident from the nature of the variations in thickness of the sandstones that the sediments were laid down on a submerging land surface of considerable relief. It was also apparent that the details of this relief were totally unlike the forms produced by stream erosion. The rocks immediately below the contact surface are as free from weathering as those which lie hundreds of feet lower. It is therefore evident that during the progress of the submergence of the granite land surface, shore 
erosion by the advancing waters has removed a part of the original land surface and altered, or rather erased, the details of relief. It was for the more exact interpretation of the forms as seen at this place that the following elementary formulation of certain general principles was undertaken.

\section{EFFECT OF PREEXISTING. TOPOGRAPHY}

When an eroded land surface is submerged and covered by later sediments the surface of contact between the two formations may be expected to have some dependence on the topography of the preexisting land. Other factors being equal, a topography of steep hills and valleys will show itself after burial in a corresponding unevenness of the surface of unconformity. The surface of contact is, of course, not visible, but a section of it appears when the formations at the line of contact are uplifted and eroded. If the outcrop be on a plane surface and the line of contact straight, the surface of contact is supposably a plane. There is, then, a suggestion, at least, that the land surface of the lower formation before submergence and burial was one of faint relief. The more the line of contact deviates from straightness (ignoring subsequent folding) the greater the presumption in favor of strong relief before submergence. These inferences very properly take into account the effect of the topography of a submerging land on the form of the surface of contact with later formations, but they leave out of consideration the important change which may accompany the advance of the sea.

\section{Factors and Conditions of the Problem}

There are two factors which determine the deviation of the surface of contact from a plane. These factors are (1) the form of the preexisting land surface, and (2) the strength of shore erosion during submergence. These elements may combine in any proportion. Hypothetically, two extreme suppositions may be made. The extreme of rapid subsidence and small wave erosion would result in leaving the original subaerial topography unaltered and retaining it as the surface of unconformable contact. At the other extreme is the complete dominance of shore erosion, whose tendency is to plane off the hills and to make the contact with the newer sediments a horizontal plane.

It should be stated here, though somewhat parenthetically, that shore erosion may, under certain circumstances, increase instead of destroy the relief of a submerging land surlace, but such conditions are exceptional. This is apparent when it is remembered that the shoreline is a contour line; that whatever straightens the contours is bringing the 
surface nearer to a plane, and that the general tendency of shorelines is to straighten themselves; hence to reduce relief. The possibility of the opposite effect depends on unequal strength of the shore rocks, and can occur only when wave erosion is cutting out bays in the weaker rocks of a rugged coast, thereby making the coastline more irregular. Even under these conditions of unequal strength of rocks, increase of relief is not universal. In the following discussion this phase of marine denudation will not be considered.

There is one further exceptional and unusual case which will not be considered in the paragraphs to follow. That is the case in which no erosive work whatever is performed by the oncoming waters. This may be exemplified by a preexisting land surface of such gentle seaward slope as to require the construction of offshore barriers in order to steepen the beach profile. But even in this case observation may sometimes detect a small degree of cliff-cutting along the new shoreline before the barrier appears. The usual case, and the only one needing consideration here, is that in which submergence is attended by the paring down of hilltops.

Subsidence alone causes the shore to shift landward at a rate determined by the slope of the land and the rapidity of crustal movement. This change of position of the shoreline will be spoken of as shifting. But the actual migration of the shoreline will depend partly on this horizontal shifting and partly on the rate of the attendant cliff-cutting. The actual rate at which the cliffs recede and the shoreline migrates may be greater or less than this shifting. The total movement of the shoreline, regardless of causes, will be spoken of as migration.

If the position of the water-level be newly assumed against an irregular land surface, the first cliff erosion causes recession which is more rapid than the mere shifting which could be caused by any possible rate of subsidence. In other words, no supposition is allowable which would engulf an island so promptly that the waves could not etch its descending slopes. This forging ahead by cliff-cutting becomes less and less rapid as the cliffs become higher, the amount of detritus yielded by each foot of recession becomez greater, and the disposing of the waste becomes an increasingly difficult task. By continual cliff-cutting against a land sloping shoreward, the cliffs will eventually become so high and their rate of recession so slow that the latter will just equal the rate at which the shore would shift landward by submergence alone.

When high cliffs have once been developed it may happen, as explained below, that their recession over a given space will be slower than mere shifting of the shoreline over the same space would have been had no cliffs been cut. The extreme of this condition is found where a 
broad horizontal surface is reached by the receding cliff. Over such a surface shifting would, of course, be instantaneous if the sealevel were as high as the level of the plain. When there is a cliff separating these two levels the rate of migration of the shoreline is, of course, that of cliff recession and no more.

\section{Illustrative Cages of submergence Conditions}

IN GENERAL

The above conditions of submergence are more conveniently discussed by assuming certain cases and indicating them diagrammatically. No one case can represent the conditions during the whole history of a submergence, but the entire history and the forms resulting may best be described in terms of these cases.

\section{CASE I. SHORE RECESSION MORE RAPID THAN SHIFTING BY SUBMERGENCE}

Assume the rate of cliff recession to be constant and greater than the shifting due to subsidence. In figure 1 let $B A$ represent the original

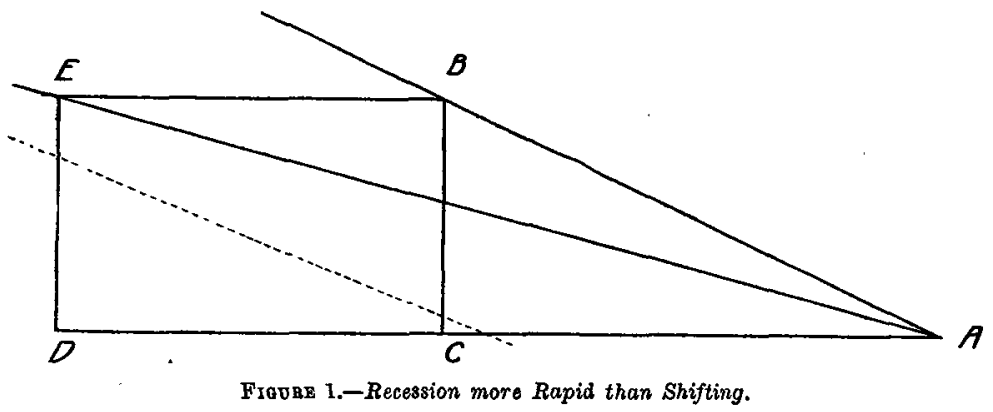

land slope. $B C$ is a certain assumed amount of vertical sinking. $C A$ is then the amount of horizontal shifting of the shoreline corresponding to the assumed amount of sinking. $D A$ is the actual amount of migration of the shoreline, due partly to cliff-cutting.

The tendency of the waves is to cut away the higher land and reduce it to a plane just as though there were no subsidence. In this case, however, the plane would not be horizontal, but inclined at an angle depending on the ratio of $A D$ and $D E$-that is, the relative rates of cliff recession and subsidence. The water's edge, which was at the outset at $A$, advances toward $E$, and in the meantime occupies all positions along the line $A E$. This line, therefore, represents the sloping surface of a denuded bench having a gentler seaward inclination than that of the former land surface. This result is due to the fact that, on account 
of active cliff-cutting, the migration of the shoreline has been more rapid than shifting due to subsidence alone would have been.

The diagram represents only an initial, broad, unbroken slope of the $l_{\text {and. If this slope be diversified by valleys and ridges, the latter will }}$ be truncated to the level of $A E$. The dotted line parallel to $B A$ in the diagram, may be taken to represent the depth of the valley bottoms. As the cliff recedes it necessarily increases in height. The new-made sea bottom approaches continually nearer to the valley bottoms which at first were beneath its level in bays. The bays become smaller and fewer, the cliff more continuous; the maturity of the shore is advancing. Finally, with the extension of the plane inland, its level may fall below that of the deepest valleys, the cliff will be continuous, and the subaqueous cut terrace will have no depressions to be filled with the sediments of the newer formation. From this line landward the surface of uncon-

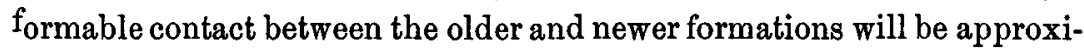
mately a plane regardless of initial topography.

This stage, in which denudation cuts below the valley bottoms, may or may not be reached. Cliff recession is accomplished against accumulating difficulties. Not only does the increasing height of the cliff yield an increasing measure of detritus for each foot of recession, but each cliff is becoming longer; the bays in which the shore drift was formerly stored in the form of spits, bars, and wave-built terraces, become fewer and smaller, and the material won from the cliffs must be disposed of by the slower process of dragging offshore. At any point of the line $A E$ the waters may prove unequal to the task of cutting a higher cliff. They must then be content to push the shore landward at the same rate at which subsidence would shift it without cliff-cutting.

CASE II. RECESSION PROGRESSIVELY RETARDED UNTIL ITS RATE EQUALS THAT OF SHIFTING

Assume as a second case that the rate of cliff recession is progressively retarded to a minimum. If the initial ratios be taken as in case I-that is, the migration of the shoreline greater than the shifting, as defined above-then the surface of marine denudation will be begun, as before, with a lower slope than that of the land surface. However, as the rate of cliff recession is diminished it will approach that of the shifting, which it will finally equal. The surface of denudation in the meantime curves upward, as represented by the line $A E$ in the diagram. When the rate of recession has become equal to that of shifting, the slope of the plane of marine denudation will equal that of the land surface. The two will be parallel and the receding cliff will have a constant height. This height will be such as to allow recession at the same rate at which the shoreline would move landward by submergence alone. 
The land surface is thus pared down to a uniform depth. If this depth is greater than the former relief, the resulting cut surface will be a plane or a broadly rolling surface, as described below. This condition is represented by taking the upper of the two dotted lines in the figure to represent the depth of valley bottoms. If the depth of paring be less than that of the valley bottoms (which may then be represented by the lower dotted line), the valley bottoms will escape the paring process and their lower parts will continue to indent the denuded surface. The diminution of relief will, of course, be equal to the constant cliff height.

In general, if denudation cuts below the valley bottoms, the entire surface of the cut terrace will be of fresh rock. If erosion fail to cut so low, the valleys will be filled, and the weathered rocks of the valley bottoms will thus be preserved on the lower side of the contact.

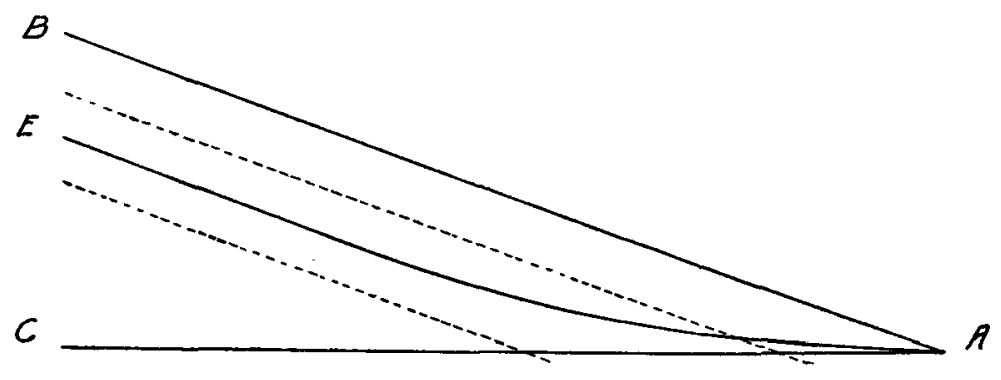

Fraura 2.-Recession retarded.

Under the conditions of case II the maturity of the shoreline will at first be advanced, but a limit of development will be reached, at which the rejuvenating effects of submergence will balance the advancement in the cycle due to erosion. If the down-cutting does not extend to the valley bottoms, there will be on the site of each headland a cut terrace whose surface will, in the main, be a plane; but the sites of the valleys, and therefore of the bays, will show depressions in the older formation, filled by sediments of the newer. If marine denudation cuts below the valley bottoms, cliffs along the shoreline will be continuous, and (with one important modification, given below) the old land surface is planed down to a level.

The modification necessary to the general statement that when cliffs are entirely continuous along a sinking coast the cut terrace thus produced has a plane surface, may be stated thus: In the submergence of a surface of hills and valleys the coastline can not well be straight. Low cliffs recede more rapidly than high ones; hence where the land is low the shore is pushed more rapidly landward. Reentrant curves are thus produced, whose possible depth is limited by several factors. In general, 
the advancing waters have an advantage on the headlands because of their exposure, and a corresponding advantage in the bay heads because the cliff there is lower. The shape of the shore tends to adapt itself by a suitable curvature, so that these two advantages shall be in equilibrium. Within limits, therefore, cliff-cutting may be entirely continuous along a sinuous shoreline. Since the form of the shoreline at any one time is a type of the contour lines on the surface of the cut terrace, in the case in hand the terrace has a fluted surface with low ridges running seaward along the line of retreat of each headland.

It is especially to be noted that the rock surface of such a cut terrace will be unweathered. The sediments laid on it, being derived partly from the cliffs and partly from active streams, may be of the coarsest sort and may be quite fresh even when feldspathic. Both these conditions clearly distinguish this case from the advance of the sea over a peneplain with its deeply disintegrated rocks. In the latter case the sediments can be coarse only when the mantle rock of the peneplain contains peculiarly resistant pebbles.

\section{APPLICATION OF CASE II TO THE AREA STUDIED}

In the area defined in the opening paragraph the contact of the Archean granite and Wyoming sandstone presents the features appropriate to that phase of case II in which denudation by cliff-cutting has cut beneath the valley bottoms of the submerging land. Ignoring the subsequent folding which made the Boulder arch, and supposing the eastward tilting due to mountain-making to be undone, the surface of the Archean-Wyoming contact has a maximum relief of perhaps 500 feet. Its undulations are of the smoothest sort, showing no slopes less than 3 miles long, with a maximum steepness of about 150 feet to the mile. These long slopes are entirely unbroken by valleys in the Archean floor, and the rocks of the latter are quite as fresh at the contact as at any greater depth. These features indicate that wave erosion by the advancing Wyoming sea pared the entire surface, even the valley bottoms, to a depth at least equal to the thickness of the zone of weathering; that in so doing the minor features of relief were erased and the major features considerably reduced. Cliff-cutting was therefore substantially continuous along the whole of the curved shoreline, and the sinking of the land was slow enough to admit of a mature shoreline topography during the stage recorded in the present outcrops.

\section{CASE III. RECESSION LESS RAPID THAN SHIFTING BY SUBMERGENCE}

Assume, as a third case, that the rate of migration is less than shifting by submergence alone would produce. On this supposition the surface 
of denudation will have a steeper slope than that of the land. This is impossible unless an initial cliff be assumed. This case therefore becomes important only as a later stage of a process begun under other conditions.

In the diagram, $B C$ represent a cliff whose recession has become less than the simple shifting of the sinking shore would be without a cliff. The recession is equal to $C D$ during a vertical subsidence equal to $D E$. During the same subsidence the shifting of the shore with no cliffs would have carried the water's edge from $A$ to $E$ through a horizontal distance equal to $D A$.

Here, again, cliff-cutting is assumed to continue at a uniform rate; hence the cut slope is a plane, and the cliff height has been reduced to zero at $E$. In actual occurrence the rate is accelerated as the height is

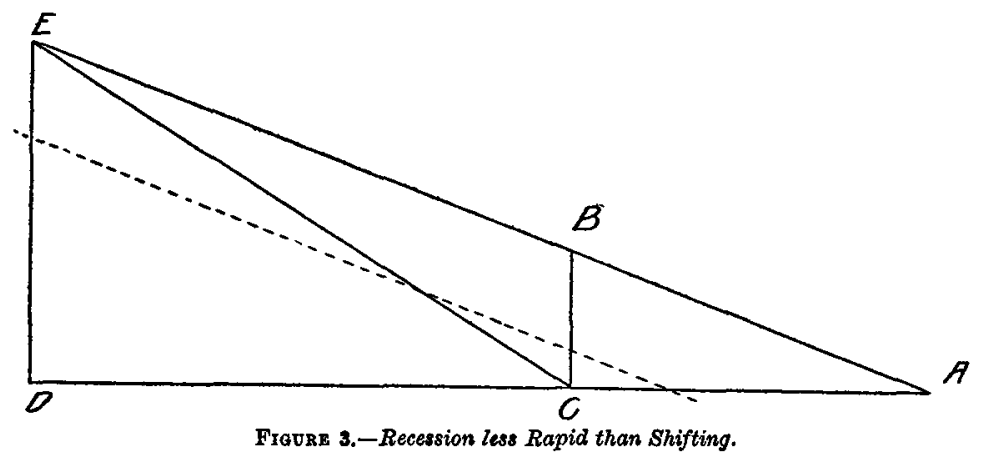

reduced, and the line $C E$ becomes a curve, convex upward and never actually intersecting the line $A B$ so long as any land remains above water. Assuming the conditions of this case after cliffs have once been developed, the surface of the cut terrace will rise landward, intersecting first the deeper valleys and then the shallower, resulting in the greater separation and subdivision of headlands and the isolation of islands. The rejuvenating effects of sinking are more rapid than advancement in the cycle of erosion, and the features of maturity give way again to those of youth.

\section{GENERALIZATION}

Abandoning straight lines, but using the principles stated above, a truer picture of the forms actually resulting from submergence may be obtained by assuming land forms of familiar type. Assume, for example, a horizontal land, but having a seaward slope near the shore. Its surface may have something of the compound curve shown in figure 4. 
The land is assumed to have considerable relief, and the submergence is assumed to be complete. Taking the process as a whole, the migration of the shoreline is equal to what it would be by shifting alone; but at different stages the actual migration and the hypothetical shifting have varying ratios.

If we assume the process to begin with relatively low initial cliffs (a common case), migration at first exceeds mere shifting by réason of excessive cliff recession (case I); the two curves representing the land surface and that of marine erosion separate; the latter is concave upward. With the decreasing rate of cliff-cutting there comes a stage where it merely equals the rate at which shifting alone would carry the shore landward (case II); the curves are about parallel and have their

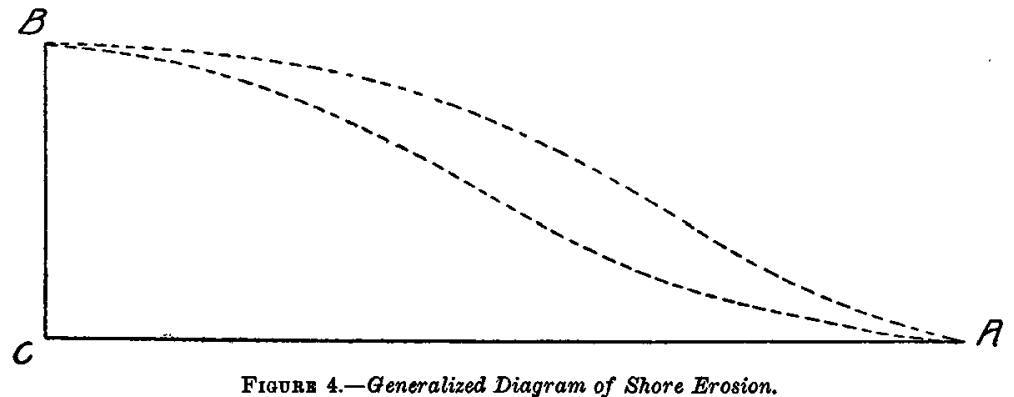

The upper curve represents the original land surface. The lower represents the surface of marine denudation.

maximum separation. Then migration becomes less than the theoretical shifting by reason of the small seaward slope of the remaining land (case III) ; the lower curve becomes convex upward and approaches the upper.

Interpreted in terms of shoreline topography, the erosive work of the sea at first advances the shoreline in its cycle, smoothing its contour, pushing back its cliffs rapidly, and increasing them in height and length. As this process grows slower by its own development, the effects of sinking begin to keep pace with those of erosion. The shore forms remain stationary in their cycle while the shoreline recedes landward. The cliffs have at this time their maximum height. With the diminution of slope of the land surface, the surface of marine denudation approaches it, the cliffs become lower, the rate of their recession is augmented, and the features of youth return. Continued sinking will at length cause the surface of the cut terrace to intersect that of the land, and submergence will be complete. 


\section{N. M. FENNEMAN-EFFECT OF CLIFF EROSION ON FORM}

If the last land to be submerged were an undissected plain, it would be narrowed by cliff-cutting at an increasingly rapid rate as the height of the cliffs was lost. If the last remnant be cut by valleys, continued submergence must subdivide it into islands, the story of each one of which will reproduce, in a manner, that of the entire land mass.

In actual experience it may be expected that a large part of all cases of submergence will be found to begin with well developed cliffs cut while the land was standing still. The height of these may not be greatly increased during the migration of the coast. In such cases the initial stages of the process represented by figure 4 are omitted. 
. 